\title{
Acaparamiento de territorios marinos y costeros: dos casos de estudio en el Caribe colombiano
}

\author{
Ocean and Coastal Grabbing of Territories: \\ Two Case Studies in the Colombian Caribbean
}

\author{
Ana Isabel Márquez Pérez \\ Universidad Nacional de Colombia, sede Caribe, Colombia
}

DOI: https://doi.org/10.22380/2539472X.573

\section{RESUMEN}

Este artículo presenta los casos de dos comunidades de pescadores artesanales raizales y afrodescendientes en Providencia y Barú (Caribe colombiano), en relación con el acaparamiento de sus territorios colectivos marinos y costeros. Expone la configuración histórica de estos últimos, a través de los usos sociales tradicionales de los ecosistemas y analiza los cambios ocasionados por el desarrollo turístico, la especulación inmobiliaria y algunas iniciativas de conservación que, en el marco de la introducción de las lógicas del capitalismo neoliberal a estos territorios, han desembocado en su progresivo acaparamiento.

Palabras clave: acaparamiento de los océanos, neoliberalismo, Caribe, comunidades afrodescendientes y raizales.

\section{$\overline{\text { ABSTRACT }}$}

This article presents the cases of two Caribbean African-descent artisanal fisheries communities in Old Providence and Barú (Colombian Caribbean), in relation to the expropriation of their customary ocean and coastal territories. It exposes the historical configuration of these, through the traditional social uses of the surrounding ecosystems and analyzes the changes caused by tourism development, property speculation and some conservation initiatives that, within the framework of the introduction of neoliberal capitalism logics to these territories, have led to their progressive hoarding.

Keywords: ocean grabbing, neoliberalism, Caribbean, Afro-descendant and Raizal communites.

Profesora de la Universidad Nacional de Colombia, sede Caribe. Antropóloga de la Universidad Nacional de Colombia con Doctorado en Ciencias Sociales de la Universidade Federal Rural do Rio de Janeiro. Su última publicación es "Memorias del mar: la conformación del territorio marítimo raizal de los cayos del norte del Archipiélago de San Andrés, Providencia y Santa Catalina, por medio de la memoria y la historia oral", en Memoria y territorio (Bogotá: Instituto Colombiano de Antropología e Historia, 2017). aimarquezpe@unal.edu.co. 


\section{Introducción}

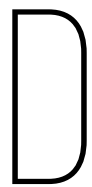

iversas vertientes de la antropología han intentado acercarse, a partir del trabajo de campo etnográfico, a las formas particulares de vida de las comunidades humanas alrededor del mundo que habitan en costas, islas, ciénagas y otros espacios acuáticos, o cercanos al agua (Acheson 1982; Adomilli y Gonçalves da Rosa 2017; Alcalá 2011; Cordell 1989; Diegues 1998; García-Quijano et al. 2015). Estas formas de vida han dependido históricamente del desarrollo de una gran diversidad de vínculos, prácticas y conocimientos asociados a los ecosistemas acuáticos, que se expresan tanto en el plano material como en el simbólico, a través de los cuales las comunidades se relacionan con los espacios en donde habitan y de los que obtienen sus medios de vida, y que han garantizado, hasta hoy, gran parte de su bienestar.

Como resultado de esta relación entre cultura y naturaleza, espacios tradicionalmente denominados de uso común, como costas, playas, manglares o arrecifes, se han convertido en parte de los territorios de las comunidades, entendidos como espacios de vida donde se insertan los procesos sociales, culturales, económicos, políticos, ambientales e identitarios, en interacción con los ecosistemas y recursos que los sustentan (Cordell 1989; Hasbaert 1998; Nietschmann 1989; Sharp 2004). Sin embargo, estas relaciones se ven hoy afectadas por diversos cambios socioculturales y económicos, como consecuencia de la incorporación de estas poblaciones, sus ecosistemas y territorios, a las lógicas del sistema capitalista y las economías de mercado y, en las últimas décadas, a los procesos asociados con el neoliberalismo (McCay y Acheson 1987; Sabourin 2011; Shiva 2003; Van der Ploeg 2008; WFFP 2014).

Si bien las comunidades afrodescendientes que hoy habitan el Gran Caribe han estado vinculadas al mercado transnacional capitalista desde muy temprano, teniendo en cuenta la importancia de esta región y de los procesos esclavistas y colonialistas que tuvieron lugar allí para la consolidación del capitalismo (Williams 2011), este vínculo fue parcial. Esto es especialmente cierto a partir de la emancipación de los esclavizados durante el siglo XIX, que dio origen a la conformación de sociedades campesinas - en el sentido dado por Van der Ploeg $(2008)^{1}$ - , en parte como un ejercicio de libertad de los recién emancipados,

Van der Ploeg (2008) y otros autores (Sevilla y González 2005; Toledo y Barrera-Bassols 2008) proponen una comprensión del campesinado no solo como un sujeto histórico sino como una forma de relación con la naturaleza, marcada por una transformación constante y mutua entre la sociedad y los ecosistemas, que busca libertad con respecto a las relaciones de explotación y la autonomía a partir de una diversidad de estrategias económicas y sociales. 
que conformaron formas de vida altamente autosuficientes, con valores comunitarios y solidarios, basados en lógicas no exclusivamente capitalistas, aun si mantuvieron algunos vínculos con el mercado (Márquez 2014; Pedraza 1984). No obstante, en las últimas décadas, estas sociedades se han transformado drásticamente a medida que los procesos de globalización económica han irrumpido cada vez con más fuerza en sus territorios y formas de vida. Esta situación se agrava con la llegada del neoliberalismo, entendido como un proceso global que busca generar y facilitar las condiciones para la acumulación del capital ${ }^{2}$ (Harvey 2007), contexto en el que muchos de los territorios y recursos de estas comunidades han empezado a recibir una atención especial.

Aunque la naturaleza se encuentra en la base del proyecto capitalista -incluso desde los planteamientos del liberalismo clásico-, en los últimos treinta años ha tenido lugar un aumento progresivo de las políticas, discursos y prácticas que buscan sujetarla al control neoliberal, en manos de actores estatales y empresas multinacionales. Si bien en cada lugar el neoliberalismo ocurre de maneras dispares, es posible identificar, mediante el análisis de estudios de caso, las formas como está sucediendo este proceso y aquellos aspectos comunes que permiten hablar de una neoliberalización de la naturaleza. Entre estos se destacan los arreglos político-institucionales que facilitan el control de partes de la naturaleza por actores económicos poderosos; la privatización de espacios y recursos a favor de corporaciones o individuos; los cerramientos, que implican el acaparamiento de recursos comunes y la exclusión de aquellos que viven en estrecha relación con estos; y la mercantilización de los ecosistemas, a través de su conversión en mercancías comprables y vendibles (Brockington y Duffy 2010; Castree 2008; Heynen y Robbins 2005; McCarthy y Prudham 2004).

En el marco anterior, el debate teórico sobre el acaparamiento de tierras ha ganado fuerza en la última década, en la medida en que se empieza a identificar una dinámica particular de adquisición masiva de tierras por grandes corporaciones, que implica la desposesión de amplios sectores sociales ${ }^{3}$ (Borras et al. 2011). Más recientemente, el debate ha incluido el acaparamiento de agua, particularmente del agua dulce, planteando que gran parte del interés por controlar

2 Harvey (2007) plantea que el proyecto neoliberal se fundamenta en la privatización y mercantilización de diversos dominios de la vida social mediante la financiarización, y la gestión y manipulación de la crisis, para garantizar un flujo de riqueza de los países pobres hacia los ricos y mantener el recorte del gasto público, especialmente en la inversión social.

3 Una parte importante de las discusiones académicas sobre el acaparamiento de tierras y aguas puede encontrarse en The Journal of Peasant Studies, revista dedicada al campesinado, en la que publican autores de diversas disciplinas, incluyendo antropólogos. En Colombia el tema ha sido discutido principalmente desde los movimientos sociales con participación de la academia (Arias y Caicedo 2016, 2017; Grajales 2011; Ojeda 2012; Vélez-Torres 2012). 
la tierra surge de la necesidad de control del agua y señalando sus impactos sobre la seguridad alimentaria (Dell'Angelo y Rulli 2018; Mehta et al. 2012). Aunque las aproximaciones al acaparamiento del agua identifican distintos tipos de agua e insisten en la existencia de diferencias cualitativas sobre ella, el análisis del acaparamiento de los océanos o del agua salada ha sido abordado por otros autores (Barbesgaard 2018; WFFP 2014) bajo la denominación de despojos azules ${ }^{4}$ (Benjaminsen y Bryceson 2012; Hill 2017), y por separado de los debates sobre el agua dulce, quizá por considerar que esta última cumple funciones diferentes y con frecuencia es asociada a las discusiones sobre despojos verdes (Fairhead et al. 2012). Algunos autores se aproximan al tema sin utilizar el concepto de acaparamiento, como Mansfield (2004), en relación con la privatización de pesquerías en el Pacífico norte de Estados Unidos y el trabajo reciente de antropólogos e historiadores chilenos sobre las pesquerías de ese país (Camus et al. 2016; Camus e Hidalgo 2017; Camus et al. 2017).

A partir de lo anterior, puede precisarse que el debate sobre el acaparamiento de los océanos se refiere a procesos de cerramiento de ecosistemas y especies marinas y costeras que, a través de políticas, leyes y prácticas, están redefiniendo y reasignando el acceso, el uso y el control de estos para apartarlos de las comunidades locales que dependen directamente de ellos, y darles prioridad a actores y procesos económicos y políticos poderosos, a escalas regionales, nacionales y mundiales (Bennet et al. 2015; WFFP 2014). Entre estos se incluyen iniciativas de conservación y desarrollo sostenible; proyectos industriales, minero-energéticos y de infraestructura portuaria; y actividades económicas como el turismo, la pesca industrial y la maricultura (Benjaminsen y Bryceson 2012; Hill 2017; Márquez 2014; WFFP 2014), que en diversos lugares del mundo están siendo usados para acaparar mares y costas.

Ahora bien, aunque desde el punto de vista analítico la separación de tipos de agua resulta útil, en la práctica la mayor parte de estos procesos están imbricados entre sí. Esto quiere decir que las dinámicas de acaparamiento de tierras, agua y océanos se superponen, si no en todos los casos, al menos en muchos de ellos (Dell'Angelo y Rulli 2018; Mehta et al. 2012). Así, el acaparamiento de tierras puede incluir espacios costeros, como playas y manglares, que tradicionalmente se conciben dentro de regímenes de propiedad diferentes a la tierra propiamente dicha (McCay y Acheson 1987); en tanto que el acaparamiento de agua puede

4 Existe una literatura creciente en lengua inglesa sobre la neoliberalización de los océanos, que en los últimos años ha empezado a trabajar su acaparamiento bajo el concepto de blue grab u ocean grab, en revistas como Marine Policy o Geoforum, en las que participan autores de diversas disciplinas, principalmente geógrafos. 
incluir el control de espacios como ríos y lagos, que comparten el mismo régimen de propiedad de playas y manglares. Además, de manera general, el acaparamiento de océanos obedece a dinámicas parecidas a las que tienen lugar con la tierra y el agua dulce, y genera impactos similares sobre la seguridad alimentaria y las formas de vida de las comunidades en general.

Este artículo busca dialogar con perspectivas antropológicas sobre el agua, un campo de estudio que gana fuerza en la disciplina, y particularmente con aquellas discusiones más recientes que abordan las relaciones de poder en torno al agua y su rol en las luchas sociales (Dell'Angelo y Rulli 2018; Mehta et al. 2012; Orlove y Rassmunsen 2015). En efecto, si existe un interés sobre la naturaleza en el proyecto neoliberal, el agua -fundamental para la vida humana en sus aspectos materiales y simbólicos- está en el centro de este, aunque las formas en que se concreta son diversas, dependiendo de los contextos ambientales, históricos y geográficos. En este sentido, las etnografías de los procesos de neoliberalización aportan a una comprensión de este fenómeno en su complejidad local y territorial, al tiempo que "nos permiten, a aquellos de nosotros que nos oponemos instintivamente al proyecto neoliberal, a mantenernos honestos y optimistas, en la medida en que concretizan, modifican y complican reclamos teóricos amplios sobre el neoliberalismo" (Castree 2008, 133; traducción propia).

En este artículo se analizan los casos de dos poblaciones localizadas en zonas costeras e insulares en la región caribe de Colombia. La primera es Old Providence y Santa Catalina, municipio del único departamento insular del país (archipiélago de San Andrés, Providencia y Santa Catalina), con una población de aproximadamente 5.000 habitantes, en su mayoría raizales 5 . Históricamente, los habitantes de las islas se han dedicado a la pesca y la agricultura, sobre todo a partir de la emancipación de los esclavizados, cuando se configuró una sociedad eminentemente campesina. No obstante, en los últimos cincuenta años, con la introducción del turismo en la vecina isla de San Andrés y posteriormente en Providencia, la pesca sufrió un proceso de especialización y ganó una gran importancia económica, mientras que la agricultura se debilitó (Márquez 2014; Pedraza 1984).

La segunda es Barú, un corregimiento rural de Cartagena (Bolívar), localizado en la isla continental del mismo nombre, con una población aproximada de 3.000 personas, en su mayoría afrodescendientes. Allí también la agricultura

5 Los habitantes del archipiélago de San Andrés, Providencia y Santa Catalina se autodenominan raizales, un marcador étnico que busca diferenciarlos de la población afrocolombiana, teniendo en cuenta las diferencias en su historia colonial británica; su tradición religiosa protestante; su idioma, el creole, una lengua criolla de base inglesa, y otras formas propias de organización social. 
y la pesca fueron las actividades más importantes hasta mediados del siglo XX. A partir de entonces, ocurrió un proceso similar al de Providencia, pues con el desarrollo del turismo en Cartagena y zonas aledañas, la pesca también se convirtió en una de las principales actividades, mientras que la agricultura casi desapareció (Durán 2007; Heckadon 1970; Márquez 2014) (véanse las figuras).

A través de la pesca y otras actividades, estas comunidades desarrollaron estrechas relaciones con el mar y la costa, que configuran territorios no solo terrestres sino también acuáticos, pero que no son reconocidos como tales por parte del Estado colombiano y la sociedad nacional. Esto en la medida en que, de acuerdo con la visión occidental contemporánea, el mar y las costas son considerados espacios públicos y más estrictamente baldíos, terra nullius, según el término legal (Cordell 1989; McCay y Acheson 1987). Y es precisamente allí donde, como resultado de la introducción en las últimas décadas de actividades asociadas al turismo, la pesca industrial y la conservación de ecosistemas, cada vez son más evidentes los procesos de acaparamiento del mar y la costa.

El objetivo de la comparación entre estas dos comunidades es mostrar cómo, a pesar de las diferencias entre contextos históricos y sociales disímiles, es posible encontrar similitudes tanto en los procesos de territorialización de los espacios marinos y costeros por parte de las comunidades, como en su progresivo acaparamiento por nuevos actores económicos y políticos. Con ello se busca arrojar luces sobre una temática que ha sido poco trabajada en el contexto nacional. En este último sentido, es de resaltar la relación entre la pertenencia étnica de los grupos analizados y la expropiación de ecosistemas que forman parte de sus territorios de vida, que evidencia un proceso de despojo con un componente étnico y racial ${ }^{6}$.

En el análisis propuesto, presentaré una discusión sobre la configuración de los territorios asociados al mar, mostrando, desde una perspectiva etnográfica, cómo las comunidades han desarrollado una estrecha relación con este. Posteriormente, analizaré de manera general una serie de dinámicas de acaparamiento de los ecosistemas señalados, a través de los cuales se evidencian procesos de acumulación por desposesión (Harvey 2007). Finalizo con una aproximación a las consecuencias que esto tiene sobre las formas de vida y el bienestar de las comunidades investigadas. 
Figura 1. Localización de las dos comunidades estudiadas

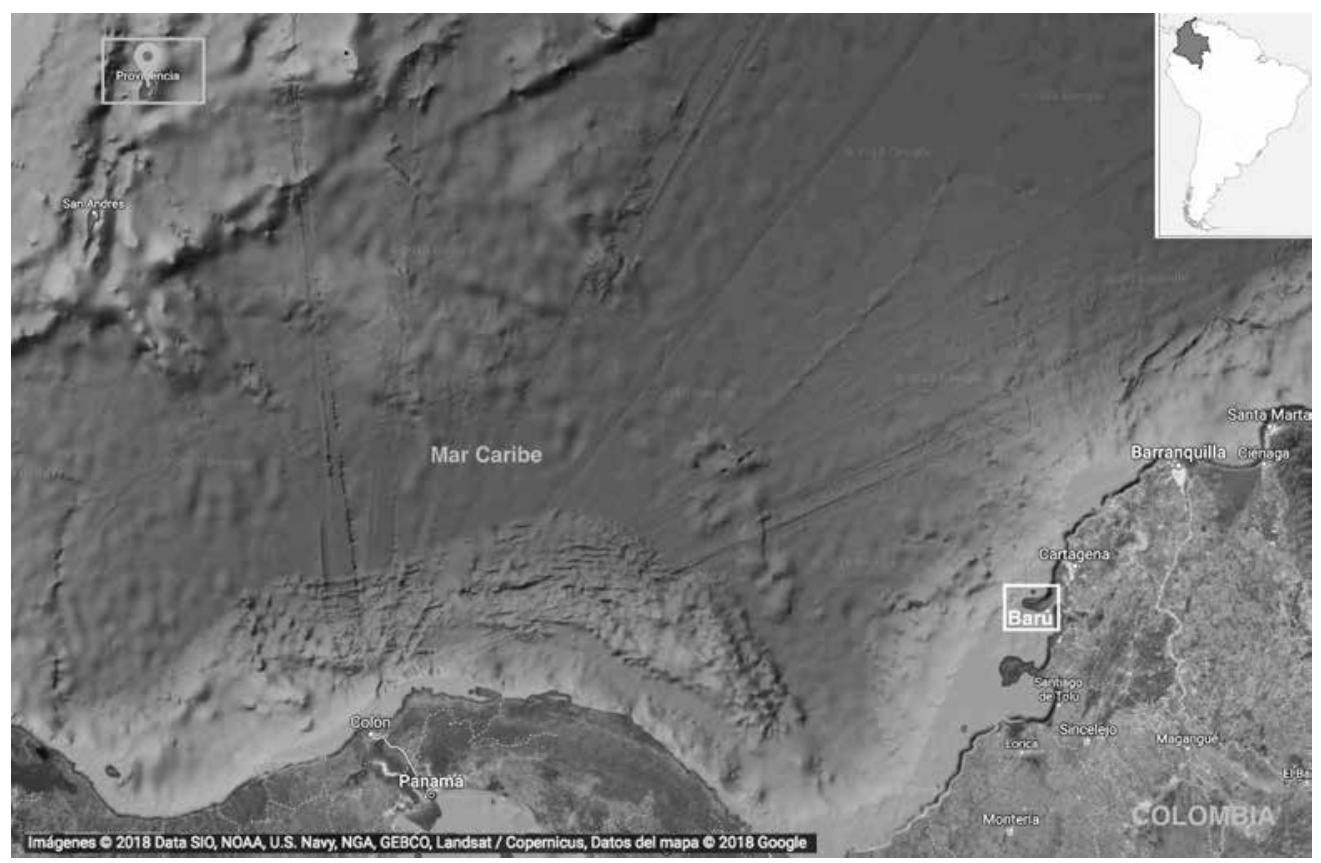

Fuente: elaboración propia con base en Google Maps.

La información presentada proviene principalmente de trabajo de campo etnográfico y etnohistórico extensivo, realizado entre 2012 y 2013 (Márquez 2014), así como de investigaciones adicionales realizadas específicamente en la comunidad de Providencia y Santa Catalina en los últimos trece años (Márquez 2005, 2012, 2013, 2017). Durante este trabajo, la observación participante se realizó en diversos escenarios relacionados con el mar - faenas de pesca de corta y larga distancia con diversas artes, regatas de embarcaciones, actividades de construcción de estas y recorridos por el territorio, así como un trabajo activo de reflexión con diversos actores de la comunidad mediante talleres de memoria-. También se desarrollaron cerca de 150 entrevistas en Providencia y Santa Catalina, y alrededor de 70 en Barú, dirigidas a pescadores, navegantes, constructores de embarcaciones y mujeres, así como a líderes comunitarios, actores institucionales e investigadores de diversas áreas con experiencia en las zonas de estudio. 


\section{Vida y territorio en mares y costas}

Los ecosistemas marinos y costeros son fundamentales para los modos de vida de millones de personas en el mundo, en términos de generación de empleo, seguridad alimentaria y, en general, la provisión de medios básicos de subsistencia, principalmente a través de la pesca artesanal (Pauly 2006). En Colombia se calcula una población de aproximadamente 150.000 pescadores artesanales en aguas marinas y continentales (OCDE 2016), de los cuales cerca de 30.000 se encuentran en el mar Caribe. Infortunadamente, la visión economicista sobre la pesca artesanal promovida por la mayor parte de las instituciones, centrada en su bajo aporte al PIB, ha invisibilizado las contribuciones de esta actividad a la sociedad en su conjunto y a las comunidades que dependen de ella en particular.

Este es el caso de las dos comunidades de las que trata este artículo, donde el mar y la costa son un fundamento de sus vidas, como lo constata el hecho de que en Providencia y Santa Catalina se reporten cerca de 300 pescadores registrados, mientras que en Barú se calculan alrededor de 140 (Secretaría de Agricultura y Pesca, comunicación personal; Medrano et al. 2016). La pesca no solo beneficia directamente a un número importante de pescadores de subsistencia, que no son evidentes en estas cifras, sino también a una porción elevada de la población, a través de las diversas actividades vinculadas a la producción, el procesamiento y el consumo de pescado y otras especies marinas. A la vez existen otras formas de interactuar con el mar, como los oficios asociados a la navegación que han sido muy importantes en ambas comunidades (Márquez 2014).

Estas relaciones tienen lugar en ecosistemas de manglar, playas y litorales rocosos, arrecifes de coral y ecosistemas pelágicos asociados, los cuales constituyen territorios marítimos que "no son simplemente un espacio de mar delimitado, sino áreas nombradas, conocidas y, en ocasiones, defendidas" (Nietschmann 1989, 60). Dos aspectos se destacan y son transversales a estas relaciones. Por una parte, el detallado conocimiento ecológico y social que se configura desde los primeros asentamientos en los siglos XVIII y XIX (Durán 2007; Parsons 1985), a partir de las interacciones con el entorno, así como de una diversidad de conocimientos - hegemónicos y contrahegemónicos, escritos y orales-, que han sido fundamentales para garantizar la vida y el bienestar en lugares aislados en términos geográficos pero no sociales.

Cabe señalar que este conocimiento está enraizado en las prácticas cotidianas de las comunidades; es dinámico, en permanente reinterpretación y transformación, y adaptable a nuevas situaciones, tal y como lo hacen sus portadores. Está distribuido desigualmente pues no todos los miembros de una comunidad 
tienen los mismos conocimientos (Agrawal 1995; Nygren 1999; Shiva 2003; Toledo y Barrera-Bassols 2008). Así, por ejemplo, las relaciones y conocimientos en torno a los espacios marinos más alejados son propios — mas no exclusivos- de los hombres, quienes suelen ser los pescadores, aunque se comparte con algunas mujeres que se han vinculado ocasionalmente a la pesca, sobre todo en Providencia. Sin embargo, no todos los hombres ni todos los pescadores tienen los mismos conocimientos. De hecho, actualmente solo una porción de los pescadores providencianos, generalmente considerados los más avezados, realiza faenas en las zonas de pesca más alejadas, lo que no obsta para que exista una memoria compartida sobre estos viajes, pues la experiencia se transfiere a través de la oralidad, incluso a personas locales que no participan de estas actividades, como las mujeres.

Lo anterior nos remite al segundo aspecto transversal, referido al papel de la memoria como un elemento constitutivo de la relación con estos espacios, que nos habla de su importancia para las comunidades y se conserva hasta hoy en la historia oral transmitida de generación en generación. Estas memorias varían de acuerdo con el desarrollo histórico propio de cada comunidad, así como con sus intereses pasados, presentes y futuros, pero en ambas permiten hacer una lectura de la importancia social de estos espacios al hablarnos no solamente del pasado, sino también del presente (Wachtel 1999).

Antes de describir las relaciones, prácticas y conocimientos más relevantes en relación con estos ecosistemas, cabe una aclaración de por qué en esta discusión se incluyen las zonas costeras que son áreas terrestres y no marítimas. La primera razón es porque tanto estas como las zonas marinas son reconocidas bajo el mismo régimen de propiedad en Occidente, esto es, como espacios públicos que, al menos en la ley, no pueden ser privatizados, aunque cada vez más avanzan procesos como las concesiones que muestran lo contrario. La segunda razón es que para las comunidades estudiadas el mar y las costas no son vistos de manera opuesta, sino como una continuidad de espacios de vida, donde tienen lugar diversas prácticas sociales, materiales y simbólicas. La tercera razón es que existen procesos de conectividad ecológica de gran importancia, que en la práctica unen, y no separan, zonas terrestres, costeras y marinas.

\section{Manglares: espacios de protección y trabajo}

Los manglares han desempeñado diversos papeles en la vida de las comunidades estudiadas. Estos ecosistemas marino-costeros están formados por bosques anfibios de árboles de mangle resistentes a la salinidad, en donde habita una gran diversidad de especies y cumplen un importante papel como guardería de mu- 
chos animales del arrecife. También han servido de protección contra el clima y posibles enemigos; para la fabricación de carbón; la caza de aves e iguanas de relevancia alimentaria; la pesca de sardinas, especialmente importantes como carnada y para consumo humano; y, en particular en Providencia, para actividades recreativas como las carreras de barquitos de concha de coco (huks boats), en época de marea alta, y los partidos de béisbol y sóftbol, durante la época seca ${ }^{7}$ (Márquez 2014; PNNOPMBL 2017).

Su papel protector es particularmente evidente en Barú, que se localiza en el interior de un estuario protegido por manglares (figura 2), solo accesible a través de tres canales abiertos por los pobladores locales, al menos desde el siglo XIX. Si bien hoy puede sonar extraño decir que el manglar protegía al poblado de enemigos, debe pensarse en lo que significó para una población que albergó esclavizados que huían de las zonas circundantes (Durán 2007; Martínez y Flórez 2010).

Figura 2. Vista de la laguna del puerto de Barú donde se observa el manglar que separa al poblado del mar

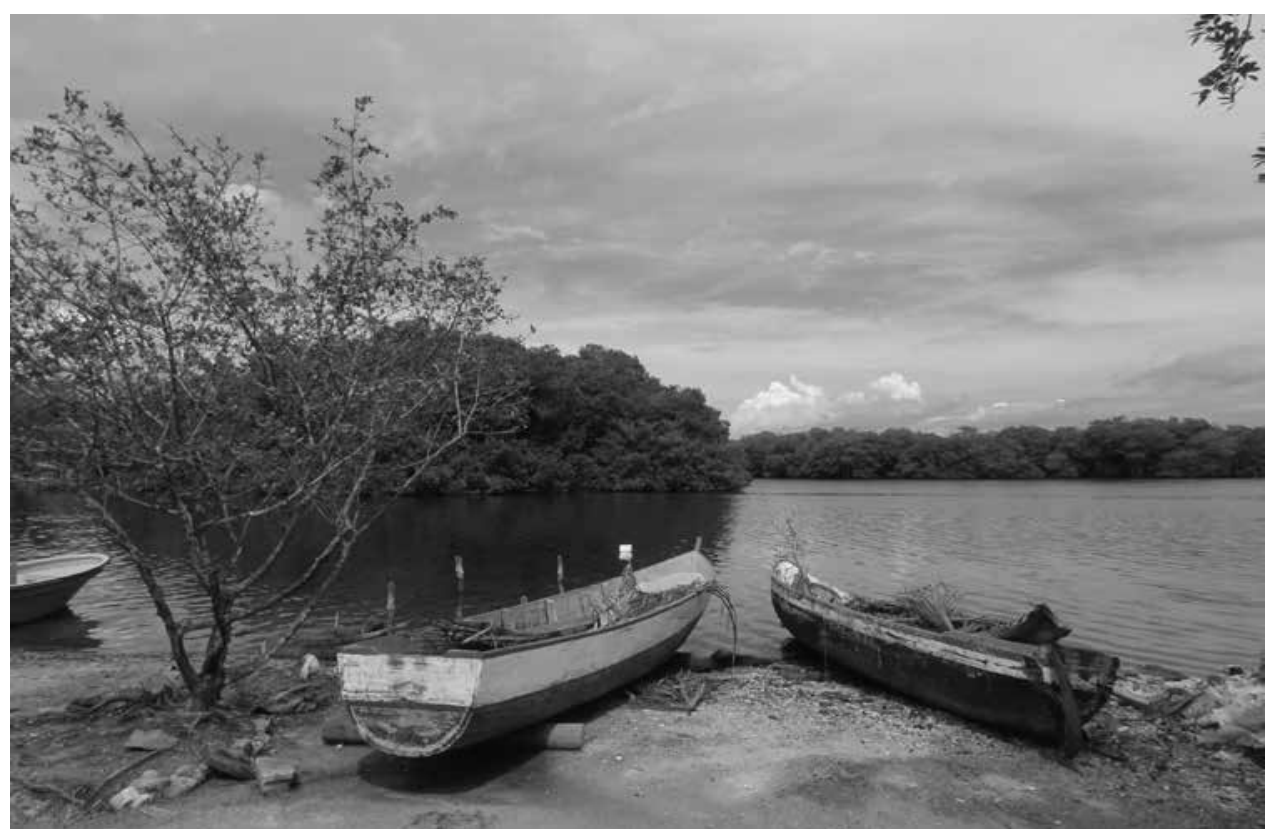

Fuente: elaboración propia.

7 En la actualidad, los dos estadios de la isla se localizan en zonas colindantes con el manglar, que originalmente fueron usadas para este tipo de juegos. Existen otros lugares donde la gente también jugaba en el manglar pero hoy están en desuso. 
Por otra parte, esta protección también se evidencia en el uso que hacen los baruleros de los manglares a través de lo que denominan puertos, lugares donde pescadores de diferentes barrios guardan sus canoas y chalupas después de un día de trabajo (figura 3). Aunque el poblado tiene un puerto principal, muchos de los pescadores poseen puertos familiares sobre la costa, cerca de los manglares y de los lugares de pesca de cada pescador, en tierras que alguna vez fueron de los baruleros y que en la actualidad pertenecen — sobre todo- a foráneos. Allí, los pescadores abren canales de acceso al mar, cortando los mangles en ciertas zonas para permitir la entrada de las embarcaciones, mientras que en otros conservan el mangle para protegerlas. Según los testimonios recolectados en campo, algunos de los puertos que existen en la actualidad fueron construidos por los abuelos y bisabuelos de los pescadores actuales y han sido mantenidos de generación en generación, lo que evidencia el papel de la memoria en la construcción de la relación con estos espacios.

Figura 3. Puerto El Cañito (Barú)

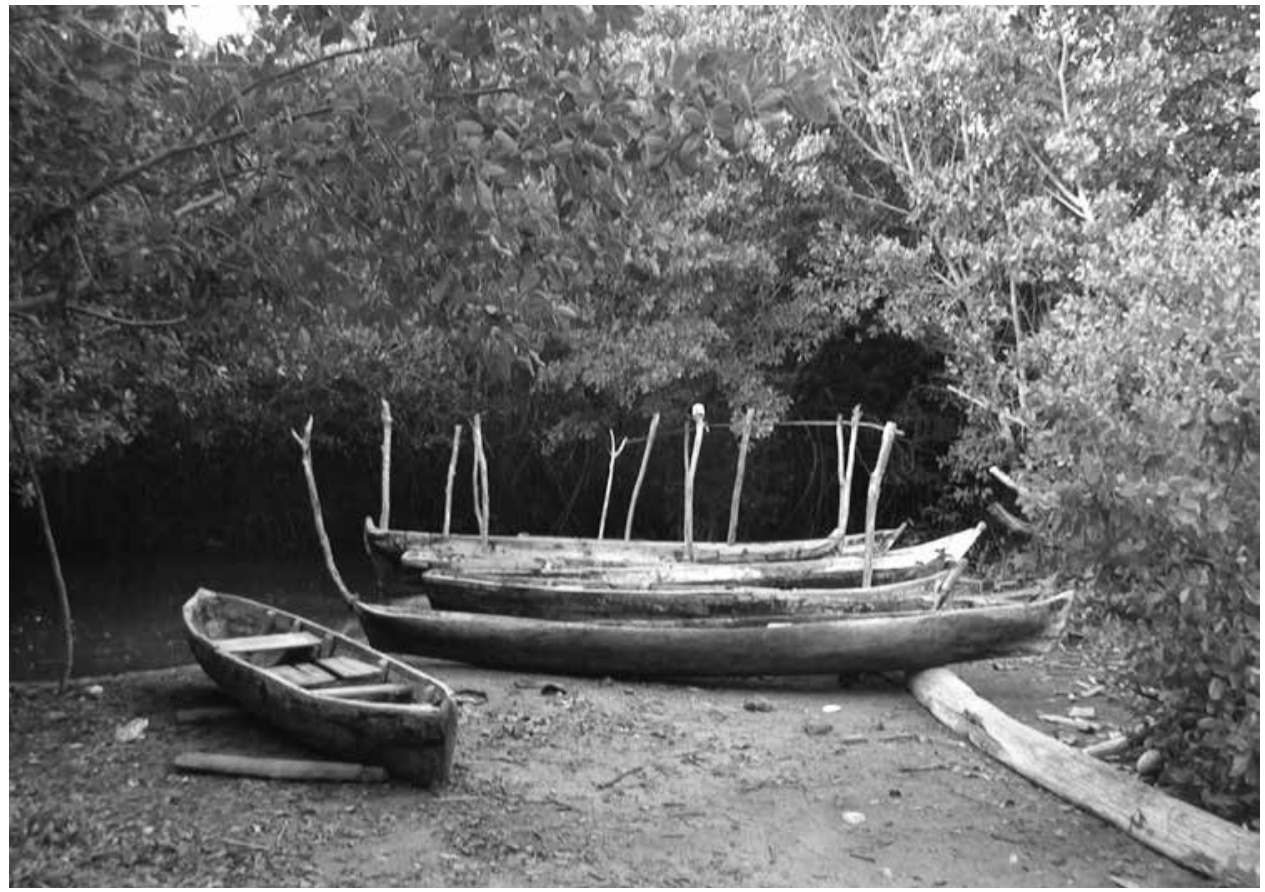

Fuente: elaboración propia.

En Providencia y Santa Catalina los manglares son menos abundantes, pero para los habitantes de Santa Catalina, donde el manglar cubre la costa 
frente a las casas, este ha constituido una protección contra el viento y las mareas fuertes. Dos relatos revelan la importancia de la relación establecida con este espacio. El primero es de un pescador de más de sesenta años quien recuerda que en su juventud, cuando por orden del gobierno local fueron derribadas áreas importantes del manglar de Santa Catalina por considerarlo insalubre, su madre solía enviarlos a él y a sus hermanos a recolectar semillas de mangle en McBean Lagoon, para sembrarlas y promover su regeneración. El segundo es de un pescador más joven, quien recuerda que su abuelo producía carbón de mangle para uso doméstico, para lo cual enviaba a los niños a cortar únicamente las ramas superiores de los mangles y aquellas que estaban enfermas, para garantizar que los árboles pudieran regenerarse y continuaran protegiendo la costa:

Mi abuelo hacía carbón. Todos los días íbamos a cortar madera del bosque para la leña [...] Después íbamos a cortar manglar, los mangles más verdes, pero mi abuelo nunca mató un mangle. Escogía las raíces que quería, especialmente si las habían invadido las hormigas negras, y las cortaba. Le quitaba las ramas al árbol que estaba enfermo y después iba a la arena hacia el mar y plantaban el horno [...] Nunca cortábamos el mangle, quedaba bajito, al ras, pero no lo cortábamos de la raíz, lo podábamos. Ahora es que crecen descontroladamente y ahora muchos se mueren porque no reciben sol, no tienen espacio, las raíces se pudren. (Entrevista a pescador de Santa Catalina, mayo del 2013)

Este testimonio nos muestra otra forma de uso del manglar reportada en ambas comunidades, relacionada con su utilización para la fabricación de carbón vegetal, una actividad vital antes de la llegada de la electricidad, puesto que servía como combustible para cocinar y planchar. Para esto se usaba especialmente el mangle rojo (Rizophora mangle), cuya madera tiene las cualidades necesarias para hacer un producto de alta calidad. En Providencia, según recuerdan los entrevistados, para sacar la madera se buscaban ramas largas, incluyendo las que colgaban sobre el mar y aquellas que presentaban signos de enfermedad; $y$ cuando se cortaba en una zona, se dejaba descansar durante algunos meses antes de volver a talar. La tala de mangle rojo era selectiva y permitía - hasta cierto punto- la regeneración del bosque, por lo que podría pensarse que era una actividad sostenible, como lo corrobora la persistencia del manglar. Más aún, como lo señala el mismo testimonio, la tala pudo haber tenido un impacto positivo sobre este ecosistema, al servir como una poda. De este modo, se evidencian formas de manejo colectivo de estos ecosistemas que permiten una lectura de las estrechas relaciones de los seres humanos con el mangle, quienes aprovecharon la naturaleza para su bienestar, al tiempo que mantuvieron las condiciones básicas para su reproducción (Márquez 2014). 


\section{La playa y el litoral: lugares de encuentro y espacios de trabajo y recreación}

Aunque en la visión occidental contemporánea — plasmada en la legislación colombiana-, espacios como la playa y la costa son bienes de uso público y no pueden ser propiedad privada de individuos (McCay y Acheson 1987), las formas tradicionales de apropiación del territorio por parte del pueblo raizal evidencian un modo distinto de entender la propiedad sobre estos. La tenencia de la tierra entre los raizales ha sido tradicionalmente familiar, esto es, una forma de tenencia colectiva privada, en donde grupos familiares conformados por un propietario y sus descendientes tienen derechos sobre la tierra. A través de las generaciones, los herederos la han subdividido, mediante pactos orales principalmente, de manera que quien lo necesita puede usar un pedazo de tierra para hacer su casa o su finca. Si bien esta dinámica se ha visto afectada en épocas recientes por la compra y venta de terrenos, tanto por locales como por foráneos, aún se mantiene en sus elementos más básicos.

Los terrenos familiares, al menos los más antiguos, fueron constituidos a partir de la emancipación de los esclavizados africanos ${ }^{8}$, cuando una porción de la tierra providenciana fue dividida entre estos últimos, mientras que otra parte permaneció en manos de los esclavistas y sus descendientes (Pedraza 1984; Wilson 1973). En ambos casos, los terrenos fueron divididos desde la montaña hacia el mar garantizando que incluyeran los diferentes ecosistemas y microclimas de la isla: el bosque más fresco en las partes elevadas, el bosque y las zonas transformadas en las partes bajas — donde se asentaron la mayor parte de las familias-y, muy importante, las playas y los litorales rocosos, desde donde era posible acceder a las zonas de pesca, recolección y a la navegación ${ }^{9}$ Esto último revela un régimen de propiedad que incluye áreas como las playas y costas que hacían parte de los terrenos familiares, lo cual era de vital importancia para una comunidad que dependía de manera directa de las actividades asociadas al mar. Además, esto evidencia una visión de la tierra, la costa y el mar como un

En las islas la emancipación siguió un curso diferente al del resto del país, pues una parte importante de las familias esclavistas liberaron a sus esclavizados en 1834, junto con el resto de las colonias británicas, mientras que otros esperaron al término de esta en Colombia en 1851.

9 Es interesante notar la existencia en la toponimia isleña de numerosos lugares denominados landing, tales como Morris Landing o Maxwell Landing, que hacían referencia a los sitios donde algunos capitanes locales dejaban ancladas sus embarcaciones durante su estancia en las islas, localizados normalmente frente a las zonas de la costa donde vivían. 
continuo: espacios de vida donde las comunidades se reproducen socioculturalmente y no como áreas opuestas y aisladas.

Dado el carácter original de tipo familiar privado de la propiedad en gran parte de las zonas costeras, los isleños también se asentaron y construyeron viviendas, como en el caso de las playas donde algunos habitan hasta hoy, en zonas que forman parte de los territorios familiares, como ocurre en la playa de Old Town en Providencia. La mayor parte de las casas que se encuentran sobre las playas fueron construidas hace tiempo y esta práctica ha ido desapareciendo en épocas recientes, aun cuando todavía se construyen quioscos para restaurantes y bares. Mientras tanto, una parte importante de las playas continúa siendo usada de manera colectiva, pues se trata de espacios de uso cotidiano. Salvo en estos espacios habitados y usados de forma permanente, es raro que las familias reclamen derechos de propiedad, aunque hay excepciones cuando surgen conflictos a partir de la aplicación de la legislación nacional que, al definir estos espacios como públicos, considera que no se deben habitar ni contener ningún tipo de edificación.

Así, la playa ha sido también un espacio comunitario de trabajo, encuentro, recreación y disfrute. Allí llegan y salen los pescadores a sus faenas, bajan las mujeres a comprar pescado o a pescar desde la orilla, y se divierten los niños pescando los fines de semana o después del colegio. Varias de las celebraciones de los isleños también tienen lugar aquí, como el $1 .^{\circ}$ de enero, la Semana Santa, el 7 de agosto o el 25 de diciembre. El paseo de playa es un ícono de la sociedad local que reúne familias y amigos en este espacio para compartir. Otras actividades que congregan a las personas aquí son las carreras de caballos y las regatas de veleros tradicionales (catboats), que involucran a diversos grupos de actores sociales, así como relaciones, prácticas y conocimientos (figura 4).

Las primeras consisten en dos jinetes que compiten recorriendo de un extremo a otro las playas más extensas de la isla. Los caballos son entrenados para que desde potros establezcan una relación con la playa y el mar, que les permita correr sin miedo al agua y a la arena mojada. Las carreras tienen lugar en ciertas fechas especiales o cuando dos hombres, propietarios de caballos, establecen un reto, que se consolida en una apuesta, y que puede alcanzar grandes sumas de dinero. La playa se convierte entonces en una fiesta donde convergen personas de los diferentes barrios para asistir a la competencia, que solo dura unos cuantos minutos pero es todo un acontecimiento social en el que participan hombres y mujeres de todas las edades.

Las regatas de catboats hacen uso de espacios tanto marinos como costeros. La playa es el espacio adonde van y vienen las discusiones entre los asistentes, que compiten en conocimientos sobre el arte de correr, así como el lugar 
Figura 4. Regata de veleros tradicionales (Providencia)

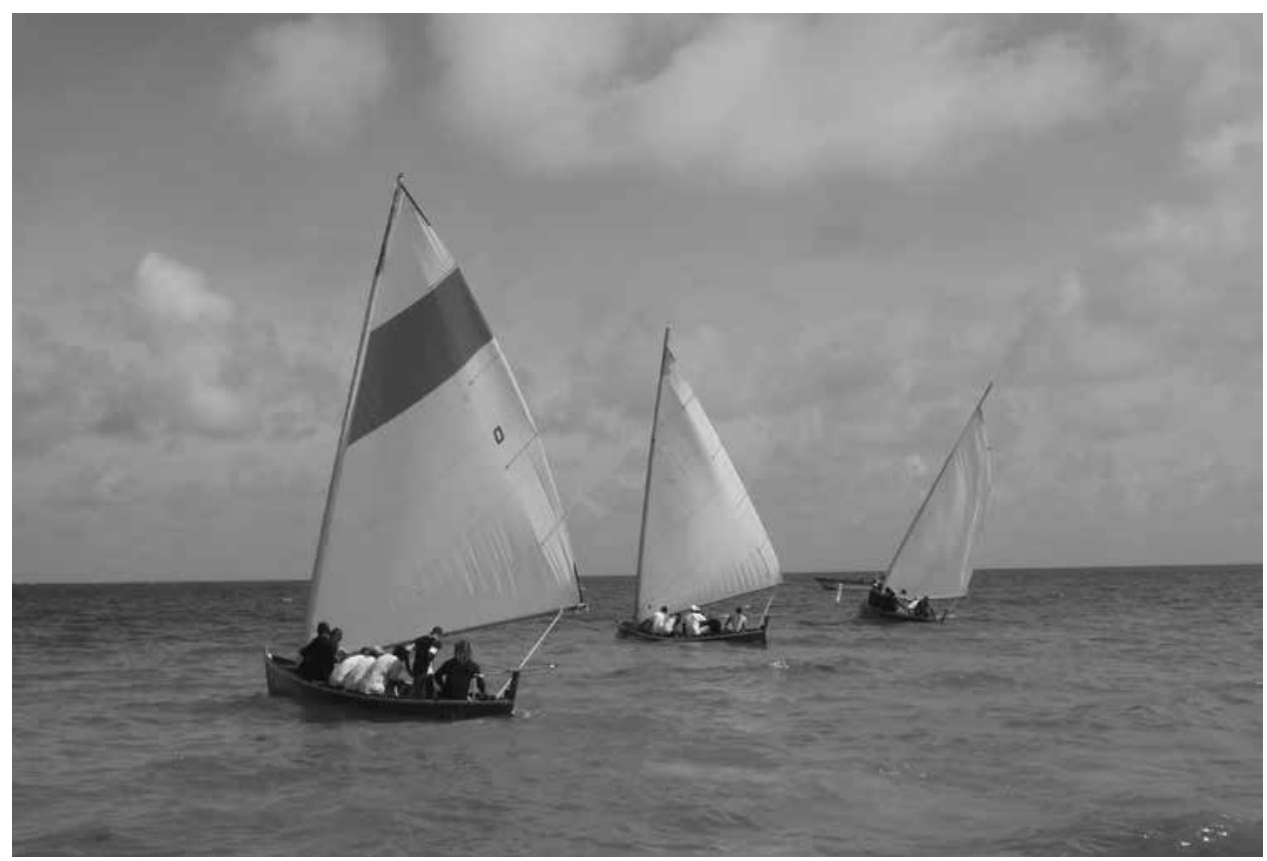

Fuente: elaboración propia.

donde se organizan las apuestas, velas y tripulaciones previas a la regata. Como los veleros recorren una distancia mayor, los asistentes deben seguirlos desde la costa o el mar, en un evento que dura aproximadamente dos horas, pero que continúa de boca en boca durante semanas.

Finalmente, las playas tienen un uso como espacio religioso pues algunas de las iglesias bautistas realizan ceremonias de inmersión de la persona que será bautizada en el mar, semejante a la realizada por San Juan Bautista con Jesús en el río. Otro aspecto religioso, tanto entre los bautistas como entre los católicos, es la tradición de bendecir las embarcaciones recién hechas y listas para entrar al mar (Márquez 2014; ORFA 2015).

Por su parte, en Barú la tenencia original de la tierra fue colectiva, a partir de la compra realizada en 1851 por los primeros pobladores, descendientes de esclavizados, y progresivamente fue dividida entre las familias (Durán 2007). Según los relatos de los entrevistados, la tierra era poseída colectivamente y asignada a quien tuviera necesidad de ella, por un consejo de mayores. Posteriormente, las familias fueron las encargadas de asignar la tierra. Aquellas que colindaban con la zona costera eran incluidas dentro de las propiedades, mientras que las 
playas eran vistas como espacios comunitarios, algo similar a lo que ocurría con el mar. Un ejemplo de ello son los puertos que estaban localizados en las zonas costeras de los terrenos familiares.

En Barú la playa está geográficamente más alejada del poblado que se encuentra frente a un estuario rodeado de manglares; no obstante, también es un espacio social relevante para sus habitantes. Uno de los usos más antiguos de las playas es la práctica de ranchar, que consiste en construir ranchos de palma donde los pescadores habitan por temporadas, mientras se dedican a sus faenas de pesca. Esta práctica persiste en otras comunidades de la región, pero en Barú ha desaparecido. También se destacan las celebraciones católicas de San Juan y San Pedro (25 de julio) y de San Pablo (29 de julio), cuando las comunidades costeras afrodescendientes festejan lo que se conoce como el Día de la Playa. Familias enteras de todos los barrios de Barú se desplazan en lanchas, motos y carros a las playas más próximas, donde se prepara comida, se consumen bebidas alcohólicas y se escucha música a todo volumen, mientras niños y adolescentes se bañan y juegan en la orilla. Otras comunidades de la zona, con las que los baruleros mantienen relaciones de parentesco y amistad, también celebran esta fiesta, por lo cual este es un importante espacio de encuentro con familiares y amigos y para estrechar lazos de reciprocidad y solidaridad aún existentes.

Una forma de apropiación más reciente de las playas y el mar, tanto por los baruleros como por los providencianos, es el turismo. En Barú sobresale el uso dado a La Playita de Cholón, el único espacio que permanece bajo el control de los pobladores locales, quienes se han organizado para evitar su ocupación por hoteles o casas de lujo ${ }^{10}$, impidiendo así ser desplazados, como ha ocurrido en el resto de las playas. Allí, con la venta de comidas y bebidas, los masajes, los trabajos artesanales y otras actividades asociadas ejercidas de forma independiente por diversos miembros de la comunidad, cerca de doscientas familias de Barú se ven beneficiadas con un trabajo autónomo (Márquez 2014). En Providencia el turismo ha sido desarrollado con gran autonomía ${ }^{11}$ por la comunidad raizal, que se encuentra vinculada en todos los niveles de la cadena, como propietarios de hoteles, posadas y restaurantes, hasta prestadores de servicios turísticos. Algunos

10 Debe recordarse que los cayos e islotes, como aquel donde se localiza Cholón, son considerados baldíos de la nación, y aunque en teoría no deben ser privatizados, en la práctica, la mayor parte del territorio de las islas del Rosario fue invadido por personas adineradas de diversos orígenes, quienes construyeron mansiones y hoteles en ellos.

11 Esto es el resultado del movimiento civil y étnico que adelantaron sectores de la comunidad providenciana por la defensa del territorio y el patrimonio cultural y natural del archipiélago desde la década de 1980, y que buscaba, entre otras, evitar lo que el puerto libre y el turismo masivo habían causado en la vecina San Andrés. 
miembros de la comunidad tienen restaurantes y bares en las playas, donde se ofrecen diariamente paseos en lancha, buceo y snorkel.

Aunque el turismo es una actividad reciente -inició hace aproximadamente treinta años-, existe una relación entre las actividades tradicionales asociadas a los espacios marinos y costeros, y las nuevas en las que una parte importante del conocimiento y experiencia asociados a la pesca, la cocina o el trabajo artesanal es puesta al servicio de las nuevas dinámicas socioeconómicas. Peron y Rieucau (1996) denominan a esto nuevas maritimidades, entendidas como el resultado de la reconfiguración de las relaciones y prácticas sociales y simbólicas de las sociedades con el mar, a partir de los nuevos procesos globales. Las nuevas maritimidades pueden verse como formas mediante las cuales las comunidades locales buscan articularse a las dinámicas económicas recientes, desde prácticas cercanas hasta aquellas con las que están familiarizados. Pero a la vez generan nuevas desigualdades, pues cada vez más los actores locales deben someterse a las lógicas y presiones impuestas por agentes externos, sean estos propietarios de casas de lujo, empresarios o turistas.

\section{Bajos, bancos y arrecifes: el mar como lugar de vida}

Si los manglares, las playas y los litorales rocosos son importantes para la vida isleña, el mar es quizá el más importante de todos. Allí se encuentra una diversidad de ecosistemas, que incluyen praderas de fanerógamas, arrecifes de coral de diversos tipos y profundidades, y ecosistemas pelágicos asociados, a lo cual se debe adicionar ciénagas, en el caso de Barú. En estos espacios se localizan los lugares de pesca de los pescadores providencianos y baruleros, quienes han desarrollado un detallado conocimiento que incluye información sobre áreas y técnicas de pesca y recolección, comportamiento de especies, zonas de mayor o menor productividad, clima, navegación y oceanografía, así como relatos históricos y memorias colectivas, entre otros. Es de señalar que estos espacios no han sido utilizados solamente para pescar, sino que forman parte de las rutas de navegación comercial que han unido a estas comunidades con otros lugares de la región, un vínculo clave para garantizar su bienestar.

En Providencia y Santa Catalina sobresale el conocimiento asociado a un vasto territorio de pesca que abarca mucho más que las áreas inmediatas, llegando hasta las islas y bancos del norte, conocidos como North Cays. Se trata de una serie de áreas arrecifales donde se localizan bancos de pesca, a una distancia 
de entre 50 y 100 millas náuticas ${ }^{12}$. Allí los isleños han estado presentes desde hace al menos 200 años, como lo evidencian el registro histórico y la memoria colectiva sobre una actividad de vital importancia que tuvo lugar en los bancos oceánicos del norte del archipiélago: la caza de tortugas.

La venta de caparazones de tortuga carey (Eretmochelys imbricata) constituyó el principal y casi único vínculo de las islas con el mercado capitalista durante el siglo XIX y aun bien entrado el siglo XX. La circulación de carne de tortuga también cumplió un papel fundamental en las relaciones de reciprocidad comunitaria y en parte explica el elevado desarrollo de las habilidades y conocimientos sobre el mar (Crawford y Márquez 2016; Parsons 1985). Estas memorias incluyen otras prácticas, como la recolección de huevos de aves - considerados una especie de delicatessen que solo era posible obtener en los Cayos del Norte-, y las estrechas relaciones desarrolladas con otros pueblos marineros de la región, como el de las Islas Caimán, de donde adoptaron una de sus principales tradiciones marítimas: los catboats. En una de estas memorias se señala que:

Los viejos de antes, que ya no viven, ellos navegaban lejos y lo hacían por tradición, porque aquí no había necesidad de ir lejos. Providencia estaba llena de peces grandes que ya no se encuentran y aun así la gente iba lejos porque les gustaba ir a los Cayos, porque se podían conseguir otras cosas que aquí no, los boobies, los huevos, las tortugas. (Entrevista a pescador providenciano, mayo del 2013)

Mientras tanto, en Barú llama la atención la utilización de una gran variedad de artes y técnicas de pesca asociadas a una diversidad aun mayor de ecosistemas como las ciénagas y estuarios, fuertemente influenciados por la desembocadura del río Magdalena, y las especies particulares de esta isla continental. Los baruleros también guardan memorias detalladas de viejos pescadores que han hecho presencia en la zona desde cuando las personas alcanzan a recordar, casi un siglo atrás, a partir de la apropiación de las islas y las zonas costeras próximas donde muchos ranchaban durante las faenas de pesca. De hecho, tanto el poblamiento de las islas de San Bernardo como el de la Isla Grande del Rosario provinieron de Barú y está relacionado con la pesca (Durán 2007; Heckadon 1970; Márquez 2014). tancia aproximada de 12 millas náuticas de tierra, lo que hasta la aparición de las nuevas tecnologías satelitales les permitía localizarse gracias a la triangulación fundamentada en la ubicación de un lugar a partir de dos puntos de referencia en tierra. En este sentido, la pesca oceánica de los providencianos es llamativa en el contexto de la pesca artesanal. 
Por otra parte, hay memorias asociadas a la época de la navegación y el contrabando, de finales del siglo XIX hasta la década de 1960 aproximadamente, cuando el transporte marítimo unía los diversos poblados de la costa caribe, desde el Urabá hasta La Guajira, y garantizaba la circulación de personas, alimentos y otros productos de interés (Durán 2007; Heckadon 1970; Meisel 1999). En esta época muchos baruleros se convirtieron en navegantes, aprovechando su herencia como pescadores y habitantes de una zona en permanente relación con el mar, actividad que permitió el ascenso económico de diversas familias locales, y de cuya importancia aún quedan como testigos mudos las lindas casas construidas en las décadas de 1930 y 1940 (Márquez 2014). Así, un viejo marinero recuerda:

Yo fui navegante desde los quince años. Primero en las chalupas que viajaban entre Barú y Cartagena, llevando frutas y vegetales que producíamos aquí. Después trabajé en barcos de motor que viajaban por la costa caribe desde Cartagena hasta el golfo de Urabá y adentro por el río Atrato hasta Quibdó, y que también llegan hasta Panamá [...] Había un comercio legal de productos agrícolas, y uno de contrabando con Panamá, a través del cual se traía loza y trago, a cambio de café. (Entrevista a pescador barulero, junio del 2013)

En ambos casos debe señalarse la existencia de una amplia geografía marítima ancestral, un detallado mapa mental del territorio de pesca, en el cual los pescadores reconocen los cambios en las condiciones marinas, las especies y los ecosistemas, y donde pueden orientarse con facilidad para encontrar sus lugares de pesca, de acuerdo con las artes utilizadas o las especies deseadas. Este mapa, que es expresión tanto del conocimiento como de la memoria, está compuesto por una abundante toponimia, configurada a través de generaciones y reconfigurada de forma permanente a medida que cada generación aporta a partir de su experiencia y conocimiento (Márquez 2014). Los nombres del lugar no solo permiten a los pescadores identificar y diferenciar sitios de pesca, sino que son muestra de la ocupación y del uso hecho por las comunidades de estos espacios. Esto se evidencia en la gran cantidad de lugares que cada pescador es capaz de recordar, asociados a nombres e historias que se repiten de generación en generación, lo que se materializa en la habilidad de localizarse en el espacio marino, incluso sin ayudas tecnológicas. Como lo señala un pescador providenciano:

Con la pesca, fueron mis abuelos los que me enseñaron y me pasaron muchas de las costumbres que ellos tenían antes. La mayor parte de los lugares de pesca donde pesco hoy es donde los viejos pescaban ancestralmente. Eso pasa de generación en generación. Mi abuelo me enseñó como si yo fuera su hijo. Él les enseñó a sus hijos y sus hijos a sus hijos, así que son cosas que van pasando. (Entrevista a pescador de Santa Catalina, mayo del 2013) 


\section{Procesos de acaparamiento de territorios colectivos marinos y costeros en Providencia y Barú}

Los procesos de acaparamiento que este artículo aborda se refieren a una serie de actividades a través de las cuales, en las últimas décadas, se ha venido redefiniendo el acceso, uso y control de los ecosistemas marinos y costeros que forman parte del territorio de las comunidades estudiadas, para excluirlas progresivamente de ellos. Estas actividades, entre las que se cuentan el desarrollo turístico, la especulación inmobiliaria, la conservación y la pesca industrial, difieren notablemente entre sí, pero tienen en común estar asociadas a un fenómeno progresivo de neoliberalización de la naturaleza, y en este caso en particular, de los mares y costas. Ello se hace mediante procesos de cerramiento, privatización y mercantilización de los ecosistemas (Brockington y Duffy 2010; Castree 2008), que promueven la acumulación de capital por parte de ciertas élites, a partir del progresivo despojo de las comunidades.

\section{Desarrollo turístico y especulación inmobiliaria}

Providencia y Barú son lugares de gran belleza natural, particularmente por sus paisajes de playa y mar, por lo que en las últimas décadas se han convertido en foco de atención del desarrollo turístico. Aunque la dirección que estos procesos han tomado es diferente para cada caso, ambos coinciden en una acelerada pérdida de los territorios marinos y costeros, acaparados progresivamente por el turismo y los desarrollos urbanísticos de lujo.

En Barú, los intereses públicos y privados sobre la zona para el desarrollo turístico se remontan a cuatro décadas atrás. En 1974, la Corporación Nacional de Turismo, institución pública encargada del tema en ese momento, inició una serie de estudios para determinar las condiciones de las poblaciones locales y cómo introducir el turismo en la zona (CNT 1974; Martínez y Uribe 1975). Aunque el desarrollo turístico planeado por la CNT nunca se concretó de forma organizada, lo que sí ocurrió fue la acelerada y desordenada compraventa de las tierras de los baruleros, que pasaron a manos de personas adineradas de diversos orígenes.

Hacia 1950, cuando los primeros compradores externos empezaron a llegar, muchas familias tenían títulos sobre porciones de tierra a nombre de alguno de los mayores, lo que aún se mantiene entre aquellas familias que conservan propiedades. Los nuevos compradores, provenientes de Cartagena y diversos 
lugares del país ${ }^{13}$, adquirieron las tierras de los nativos -en los casos en que estos tenían títulos-, o simplemente se autoproclamaron dueños de estas, como ocurrió en muchas de las islas e islotes del archipiélago del Rosario, donde no había asentamientos permanentes. Se generó así un proceso de especulación y las tierras fueron compradas a precios muy bajos a los baruleros, con la expectativa de obtener una ganancia posterior con el auge del turismo. La compra fue hecha de manera desigual, pues los compradores externos aprovecharon la prevalencia —hasta más allá de 1950- de economías de autoconsumo e intercambio en estas comunidades, así como la existencia de una relación con la tierra que tradicionalmente no había estado mediada por el dinero, para apoderarse del territorio por precios muy bajos frente a la mirada impávida de las autoridades y, con frecuencia, con su anuencia (Consejo Comunitario de Barú 2017; Márquez 2014)

Debe aclararse que las sociedades campesinas y pescadoras, como las de Barú y Providencia, asignan a la tierra un valor moral y un rol social que supera las connotaciones económicas y utilitarias que tiende a imponerles el capitalismo. Tales valores asociados a la tierra forman parte de una ética campesina, entendida como una forma de percibir las relaciones de los humanos entre sí y con las cosas, que enfatiza los valores de uso y no de cambio (Sabourin 2011; Woortman 1990). Esto explica en gran parte por qué la gente no supo cómo enfrentar fenómenos como la especulación de la tierra, que ocurrieron en el marco de un proceso mayor de desestructuración de sus propios sistemas de reciprocidad y solidaridad, como resultado de la transición hacia economías de mercado.

Desde entonces la especulación ha aumentado y ha generado presión para que los locales vendan, de modo que en la actualidad el territorio en posesión de los baruleros es casi exclusivamente la zona urbana del poblado, con algunas excepciones en la zona rural, lo que restringe cada vez más los espacios para la agricultura o la pesca. Por su interés para el turismo de sol y playa, las primeras tierras que se vendieron fueron aquellas localizadas sobre la costa y, en consecuencia, los accesos a gran parte de las costas, las playas e incluso los manglares han sido privatizados mediante cercas, portones y murallas que encierran casas

Las relaciones entre los baruleros y los nuevos propietarios están marcadas por tensiones económicas y raciales, ya que la mayoría de compradores externos son personas adineradas y fenotípicamente "blancas". Dependiendo del contexto, los baruleros establecen relaciones tanto de subalternidad como de resistencia. abstenerse de inscribir títulos en la zona norte de la hacienda Santa Ana en la isla de Barú, "ya que encontró varias irregularidades en negocios jurídicos recientes de unas tierras sobre las cuales existía un título de propiedad en proindiviso de las comunidades negras" (Consejo Comunitario de Barú 2017). 
de lujo y playas, y excluyen física y simbólicamente a los baruleros de lo que antes fue parte de su territorio ${ }^{15}$ (Consejo Comunitario de Barú 2017; Márquez 2014).

Entre los lugares progresivamente acaparados se encuentran los puertos de los pescadores en los manglares, las zonas donde antiguamente se ranchaba, zonas de recolección de moluscos como la cigua (Livona pica) y captura de sardinas para carnada, e incluso las playas para el disfrute de los pobladores. Esto tiene implicaciones en el desarrollo de actividades de importancia económica y rompe progresivamente las formas tradicionales en que los baruleros se han relacionado con su territorio. Los habitantes locales deben pedir permiso a los nuevos propietarios para acceder a los lugares de trabajo o desplazarse a nuevos espacios, cada vez más escasos. Algo similar ocurre con las actividades turísticas de los baruleros que, con excepción de la Playita de Cholón, tienen lugar en zonas costeras privatizadas. Allí también es necesario solicitar autorización a los gerentes o propietarios de casas y hoteles para llevarlas a cabo y hacerlo de acuerdo con los parámetros que estos establecen ${ }^{16}$. Según la Ley 9 de 1989, las playas son espacios públicos y territorios comunales para el uso de las comunidades, pero en la práctica se han convertido en lugares privados para el disfrute de turistas nacionales y extranjeros.

El acaparamiento avanza con el arribo de grandes proyectos turísticos de lujo, que promueven modelos cada vez más excluyentes en zonas ya convertidas al turismo, pero todavía usadas por las comunidades ${ }^{17}$. Crece la presión de los nuevos propietarios por apropiarse de estos espacios y para eliminar la presencia de los nativos y las embarcaciones de los pescadores, poniendo obstáculos para que no desarrollen actividades "incómodas" para los turistas, como la venta informal de artículos de playa, artesanías o comida ${ }^{18}$. Esta situación refuerza

15 En el 2017, el Consejo Comunitario de Barú, con el apoyo del Centro Nacional de Memoria Histórica, elaboró un documento que señala los conflictos que ha vivido la comunidad como resultado de la imposición de un modelo de desarrollo excluyente. En la actualidad se adelantan más de doce megaproyectos turísticos o portuarios en la isla, sin contar las propiedades más pequeñas de personas adineradas.

16 Por ejemplo, quiénes, qué días, en qué horarios o cuántos vendedores pueden hacer presencia en un lugar.

No existen datos exactos sobre el porcentaje de playas privatizadas. A partir del trabajo de campo etnográfico, se puede decir que en la actualidad los baruleros solo tienen acceso a dos playas que no son privadas: la Playita de Cholón y la Playa de los Muertos, sobre la bahía de Barbacoas, donde no hay actividades turísticas. Los baruleros están adelantando un proceso para desarrollar turísticamente Playa de los Muertos, pero temen que con la eventual apertura de la carretera esta sea acaparada por actores externos (Consejo Comunitario de Barú, comunicación personal). 
la histórica condición de exclusión, discriminación racial y desigualdad social y económica, que comparten diversas comunidades afrodescendientes del país y que se sustentan en estereotipos de lo "negro" como "sin educación", "salvaje", "inculto" o "subdesarrollado" (Mosquera et al. 2007).

En Providencia la situación es un poco diferente, pues desde la década de 1980 los pobladores nativos iniciaron una lucha por la defensa de su territorio y su derecho a permanecer allí, en respuesta a los efectos sociales y ambientales que han generado el puerto libre ${ }^{19} \mathrm{y}$ el turismo masivo a San Andrés. Uno de los primeros actos de resistencia fue la lucha contra una serie de grandes proyectos turísticos de inversionistas externos que, apoyados por el Estado, buscaban promover un modelo de turismo masivo y alterar las formas de vida locales. Entre estos se encontraban un centro de buceo, una base de guardacostas y dos megahoteles que fueron combatidos y expulsados entre 1990 y 1995 (Rivera 2012), lo que dio origen al Movimiento de Veeduría Cívica Padre Martin Taylor, que continúa desempeñando un papel de gran relevancia en la defensa del territorio raizal $^{20}$.

Desde entonces, algunos sectores de la comunidad empezaron a hablar de turismo comunitario y desarrollo sostenible, y lograron que la mayor parte del turismo continuara en manos locales y que, en el 2000, la Unesco declarara oficialmente al archipiélago como reserva mundial de la biosfera. Esto le dio un giro a la gestión local, pues la reserva de biosfera representa un compromiso del Estado y la ciudadanía con un modelo de desarrollo alternativo y sostenible, que permitió promover procesos orientados a proteger la isla y a sus habitantes. Pero este modelo también se ha insertado cada vez más en el marco de la

cartagenero, que a su vez es territorio de las comunidades de Santana y Barú. El proyecto propone sustituir los restaurantes de madera localizados en la playa, de propiedad de santaneros y baruleros, que se consideran antiestéticas y poco higiénicas, por nuevas construcciones que forman parte del complejo turístico, y que serían prestadas a los antiguos propietarios para que continúen desarrollando sus actividades.

19 En 1953, el presidente Gustavo Rojas Pinilla declaró a San Andrés puerto libre, como una estrategia para dinamizar la economía local, afectada severamente en las décadas anteriores, y para profundizar el proceso de asimilación que desde inicios del siglo XX había buscado "colombianizar" a los isleños (Parsons 1985; Vollmer 1992). La medida afectó todas las instancias de la vida local, incluyendo "la migración masiva de colombianos continentales, la persecución de los protestantes, el robo y la expropiación de tierras a la población nativa, la discriminación basada en las diferencias lingüísticas y culturales, el desplazamiento y la aculturación" (Márquez 2014, 22).

20 Desde la década de 1990 hasta la actualidad, sectores de la comunidad providenciana se han opuesto a decenas de megaproyectos con éxito. Los últimos procesos exitosos fueron dos fallos constitucionales emitidos en el 2015 y el 2017 que reconocen que dos proyectos estatales, el spa y el Teatro Midnight Dream, violaron el derecho a la consulta previa, así como una acción popular que impidió la ampliación del aeropuerto, considerando que esto servía a intereses externos y afectaba el modelo de desarrollo propio de la comunidad. 
neoliberalización de la naturaleza, que sostiene que la solución a los problemas ambientales depende, en lo fundamental, de su mercantilización.

A pesar de los logros de los providencianos en la defensa de su territorio, las islas enfrentan una situación cada vez más compleja, a medida que las formas de vida tradicionales pierden fuerza y aumenta el peso de las influencias y los intereses externos. Por una parte, continúan las presiones de inversionistas nacionales y extranjeros que ven en las islas un lugar ideal para sus proyectos, desconociendo las luchas locales por la autonomía sobre el territorio y las actividades económicas. Por otra parte, existe una disputa dentro de la comunidad por el modelo de desarrollo a seguir; mientras unos defienden la necesidad de proteger el entorno y la cultura local como una garantía para la supervivencia del pueblo raizal en tanto comunidad étnicamente diferenciada, otros abogan por un modelo de desarrollo convencional orientado hacia el turismo masivo. Esta última visión es alimentada por el Estado, que promueve un modelo de turismo "sostenible" o "ecológico", que en realidad incorpora estos territorios a las dinámicas turísticas y de desarrollo predominantes y que prioriza el crecimiento económico, sin considerar las externalidades sobre la naturaleza y la sociedad. Algunos raizales con experiencia como migrantes laborales en otras islas del Caribe o en barcos de turismo consideran que el turismo masivo puede ser una opción económica importante, pero pocos son conscientes de las desigualdades económicas, sociales y étnicas que tales modelos implican para las comunidades locales.

Como resultado de la especulación, cada vez más personas en la comunidad ponen a la venta sus tierras, especialmente aquellos que tienen porciones considerables. Aunque existen mecanismos que protegen el territorio raizal, incluyendo algunos de orden nacional — como la consulta previa- y otros de orden local - como el esquema de ordenamiento territorial, que regula el uso del territorio, y el Decreto 2762 de 1991, que adopta medidas para controlar la densidad poblacional en el archipiélago-, la pérdida del territorio en manos de personas ajenas a la comunidad es cada vez mayor ${ }^{21}$.

21 Las normativas mencionadas han moderado la venta de tierras en Providencia pero muchas personas han encontrado la forma de burlar la ley. Por ejemplo, nuevos compradores promueven entre los locales figuras ilegales como el "fraude a la ley", que consiste en comprar tierras y obtener licencias de construcción a nombre de miembros de la comunidad que se prestan para ello a cambio de un pago, lo que aumenta las divisiones internas. Esta práctica se ha popularizado hasta tal punto que, pese a ser ilegal, algunas personas de la comunidad ofrecen a los visitantes la posibilidad de comprar tierras con casas ya construidas. 
En Providencia los casos de privatización del mar y la costa no son tan abundantes ni evidentes como en Barú, pero empiezan a surgir conflictos entre los nativos y los nuevos propietarios externos a causa de la desaparición de formas tradicionales de propiedad y uso que incluían a la playa y la costa, y de los cerramientos de zonas costeras que impiden el acceso a lugares cotidianos. Tal es el caso de una pequeña playa del sector de Maracaibo donde la gente de la comunidad solía acudir a bañarse, pero hoy se encuentra cercada por los nuevos propietarios del predio colindante, quienes no han abierto el paso a pesar de las protestas de la comunidad. También existen conflictos entre la comunidad e instituciones como la Dirección Marítima Nacional (Dimar), que busca reubicar a algunos pobladores locales cuyas casas se encuentran en zonas de playa, argumentando que se trata de zonas de alto riesgo y espacios públicos propiedad de la nación. Curiosamente, la Dimar no ha hecho lo mismo con personas ajenas a la comunidad que han construido ilegalmente en zonas costeras o que han cerrado el acceso a ellas. Finalmente, proyectos como una posible marina en la bahía de Providencia amenazan con expropiar porciones de costa y de mar, que continúan siendo usadas por pescadores, niños y vecinos.

\section{Iniciativas de conservación y desarrollo sostenible}

Por su atractivo biológico y ecológico, Barú y Providencia han ganado atención para la conservación de sus ecosistemas, para lo cual se han introducido iniciativas de protección del entorno natural. El conflicto con las comunidades surge en la medida en que estos lugares pasan a ser concebidos como intocados e intocables, donde los humanos no han estado o no deberían estar. Tal postura ignora la presencia histórica de las comunidades, así como sus diversas formas de relación con los ecosistemas, muchas de las cuales han contribuido a su funcionamiento (Diegues 2001).

En Barú, el Parque Nacional Natural Corales del Rosario y San Bernardo (PNNCRSB), creado en 1977, protege 120.000 hectáreas de ecosistemas marinos y costeros, en cuya zona de amortiguación habitan varias comunidades afrodescendientes. Barú no se encuentra dentro del parque pero la totalidad del territorio de pesca ancestral barulero sí lo está. Esto ha creado un conflicto permanente con la comunidad, especialmente a partir de la década de 1990, cuando el PNNCRSB empezó a consolidar el área de conservación, con la apertura de oficinas en Cartagena e Isla Grande y la contratación de funcionarios. Desde entonces, al menos en la práctica, los pobladores de Barú, y especialmente los pescadores, se convirtieron en un problema ya que, según la normatividad, la pesca, salvo aquella 
con línea de mano destinada exclusivamente para subsistencia ${ }^{22}$, está prohibida dentro del parque. La declaración de algunas zonas como intangibles ${ }^{23}$ dentro del área complica aún más la situación, pues restringe de manera específica el acceso a lugares de especial importancia para los pescadores. Ahora bien, dado que el parque carece del presupuesto para garantizar el control y vigilancia de las áreas protegidas, la persecución a los pescadores solo ocurre por temporadas.

El que estas áreas constituyan el territorio de pesca barulero nunca ha sido tenido en cuenta por el Estado, lo que mantiene y agudiza el conflicto. Es innegable que la pesca artesanal ejerce una presión sobre los ecosistemas, especialmente a partir de la intensificación de su vínculo con las economías de mercado. Pero esto no elimina su valor social, cultural y económico para estas comunidades, ni la existencia de relaciones particulares con los espacios marinos y costeros. En este sentido, las medidas de conservación han terminado acaparando el territorio de pesca de los baruleros, sin considerar sus necesidades materiales y simbólicas ni ofrecer opciones para reducir la presión que estos ejercen sobre los ecosistemas.

Lo anterior se complica por los vínculos que existen entre la conservación y el turismo, y el argumento de que este es una solución a los problemas de la conservación o una vía hacia el desarrollo sostenible. Pero, como lo señalan Duffy y Moore (2010), esta actividad permite identificar, abrir y colonizar nuevos espacios para el capitalismo. En Barú, observamos cómo el Estado que excluye a las comunidades de sus territorios marinos y costeros en nombre de la conservación es el mismo que promueve un desarrollo turístico de alto impacto sobre el entorno y permite que actores poderosos actúen sin respetar las regulaciones del parque y su zona de amortiguación -incluyendo la pesca deportiva en zonas intangibles y la tala y relleno de manglares para la construcción de hoteles y casas de lujo-.

Por su parte, en Providencia y Santa Catalina coexisten dos modelos relacionados con la conservación y el uso sostenible de la naturaleza: el Parque Nacional Natural Old Providence McBean Lagoon (PNNOPML) creado en 1995 y la Reserva de Biosfera Seaflower (RBS), la de mayor proporción marina del mundo

El Plan de Manejo del PNNCRSB define la pesca de subsistencia como aquella realizada para proporcionar alimento a quien la ejecuta y su familia (UAESPNN 2006). Aunque todas las actividades de los pescadores artesanales en la región encuadran en esta definición, ya que la venta de pescado es la base que garantiza la alimentación de cientos de familias pescadoras, el concepto del plan se refiere exclusivamente a la pesca para autoconsumo, una práctica que hoy solo existe en contadas ocasiones.

En Isla Tesoro e Isla Rosario, sobre todo en esta última, que tradicionalmente ha sido un lugar de captura de sardinas para carnada. 
que incluye entre sus mecanismos de manejo un Sistema de Áreas Marinas Protegidas (AMP).

El PNNOPML abarca una parte de la laguna arrecifal y el arrecife barrera, así como cuatro cayos y el mayor relicto de manglar de la isla. En su interior quedaron incluidas algunas de las zonas de pesca artesanal más antiguas, así como lugares de recreación local y de turismo. Aun cuando todos los PNN tienen la misma política excluyente en relación con las comunidades locales, el PNN de Providencia no ha sido tan conflictivo pues ha logrado regular las actividades turísticas y la pesca artesanal con relativo éxito, posiblemente por las mismas condiciones locales que facilitan la participación local de los isleños ${ }^{24}$.

Lo que ocurre en relación con la RBS es más complejo, considerando que la declaración del archipiélago fue propuesta desde las islas, que la mayor parte de los encargados de su gestión son locales, y que esta abarca todo el territorio terrestre y marítimo del pueblo raizal. Aun cuando las reservas de biosfera son un modelo de desarrollo sostenible, en la práctica la RBS ha sido pensada y aplicada por la institucionalidad local como un modelo de conservación de los recursos naturales, que convierte a la población local en un obstáculo para sus objetivos y no en un actor fundamental del proceso. En consecuencia, las políticas y regulaciones tienden a ser excluyentes y con frecuencia ignoran las formas de apropiación social del territorio configuradas durante siglos. Esto también implica ignorar el conocimiento y la experiencia local en torno a los ecosistemas - de gran importancia para el cuidado de las islas hasta la aparición de la legislación ambiental- y la incapacidad de incorporarlos de manera efectiva en los procesos de gestión de los ecosistemas.

El conflicto entre la comunidad y la institución encargada de la RBS se debe a que la reserva se ha convertido en un obstáculo para el desarrollo de las actividades diarias, y aunque muchos comprenden e incluso defienden la necesidad de cuidar los ecosistemas y las especies de las que deriva su sustento, existe un reclamo por la falta de inclusión real de una comunidad que lleva siglos habitando el territorio. Este reclamo alude a las políticas prohibitivas y no democráticas; a la ausencia de alternativas frente a las prohibiciones y regulaciones; y a la aplicación desigual de la ley, dado que la población nativa es perseguida o se le restringen sus actividades mientras que con frecuencia personas o intereses externos a la comunidad, con poder económico o político, actúan con impunidad. Nuevamente, nos enfrentamos a una situación en la cual los mecanismos

Cabe señalar que la declaratoria del PNNOPML fue promovida por un sector de la comunidad providenciana como una estrategia para impedir la construcción de una serie de megaproyectos en lo que hoy es su zona de amortiguación. 
de conservación terminan sirviendo a intereses del proyecto neoliberal, en una escala menor que en el caso barulero.

Una de las grandes contradicciones dentro de la RBS es la presencia de pesca industrial en los Cayos del Norte del archipiélago ${ }^{25}$, donde se localiza una parte importante de las Áreas Marinas Protegidas (AMP). La pesca industrial es una actividad insostenible (Chauenpagdee y Pauly 2004) y es inexplicable que siga estando permitida y se practique en una reserva de biosfera — situación agravada por la ausencia de controles efectivos por parte de las autoridades competentes-.

Para los pescadores artesanales, la pesca industrial es una forma más de acaparamiento, pues los industriales explotan recursos que les pertenecen, al tiempo que compiten de forma desleal con ellos y degradan drásticamente los ecosistemas, empleando métodos prohibidos ${ }^{26}$, pescando especies en veda y sobrepasando las cuotas asignadas. La pesca industrial y la política pública de asignación de cuotas que permite su ejercicio en el archipiélago son otra forma de neoliberalización de la naturaleza, y en particular de los océanos (Mansfield 2004). Si bien con el fallo de la Corte Internacional de Justicia del 2012 gran parte de la flota industrial abandonó San Andrés, la problemática continúa (Márquez 2014; Pedraza 1984).

\section{Conclusiones}

Si la neoliberalización de la naturaleza debe entenderse como un proceso que cambia de acuerdo con los contextos en los que ocurre (Castree 2008), la antropología nos permite acercarnos desde una perspectiva holística a las particularidades históricas, sociales y culturales de cada situación concreta, reivindicando además la perspectiva de los actores sociales locales. Así, la mirada etnográfica posibilita generar una perspectiva desde lo local que, al mismo tiempo, sirve para entender procesos socioculturales más amplios y complejos en la escala global, como el neoliberalismo.

En este sentido, con los casos analizados, intenté ejemplificar situaciones que se repiten cada vez con mayor frecuencia en muchos lugares de la región y que ameritan una mayor atención por parte de las ciencias sociales en el país. Con ello espero aportar también a una discusión sobre el agua y su estudio

Los bancos Quitasueño, Serrana y Roncador.

Como los compresores de buceo y los palangres horizontales, también conocidos como long line, que causan un alto impacto sobre el entorno marino. 
antropológico, considerando precisamente aquellas situaciones de injusticia y desequilibrio de poder que marcan la relación entre las sociedades contemporáneas y la naturaleza, y en las que el agua desempeña un papel central. Allí encontramos ejemplos de algunas de las principales formas de neoliberalización de la naturaleza, como la privatización de playas y manglares para el desarrollo turístico y de lujo, el cerramiento de ecosistemas y especies a través de la prohibición de actividades como la pesca o el acceso a ciertos lugares, y la asignación de un valor exclusivamente monetario a espacios cuyo significado para las comunidades va mucho más allá del dinero.

Los dos casos tienen en común el choque entre dos formas de relación con el entorno y de comprensión de los territorios acuáticos, así como el carácter etnizado de la desposesión. Por una parte, están las comunidades que a través de su vida cotidiana han convertido al mar y la costa en lugares de vida y en su territorio, y de los cuales se deriva una parte importante de sus medios de vida. Por otra parte, se encuentra el Estado junto con empresas y élites locales y nacionales para quienes el mar y las costas son un espacio público, lo cual resulta útil para el proyecto neoliberal que ve en estos lugares una frontera en expansión para la acumulación de capital. Las comunidades solo forman parte del proyecto en la medida en que acepten dócilmente los procesos graduales de privatización de sus lugares de vida y se vinculen como mano de obra barata a los nuevos desarrollos turísticos y portuarios. Estos procesos profundizan las condiciones históricas de desigualdad y exclusión de las poblaciones afrodescendientes (Vélez-Torres 2012).

Los dos casos también nos muestran cómo la conservación y el desarrollo turístico e inmobiliario - sin aparente relación - terminan siendo dos caras de la misma moneda. Al promover un desplazamiento de los usos de los ecosistemas a partir de una valoración simbólica distinta de aquella de las comunidades, la conservación genera lo que algunos autores denominan la apropiación por apreciación (Brockington y Duffy 2008) o, más correctamente, la desposesión por apreciación. Esta implica la exclusión de las comunidades locales de sus territorios, al tiempo que se generan las condiciones apropiadas para el ingreso de nuevos actores: empresarios hoteleros, propietarios de casas de lujo y turistas. Mientras actividades tradicionales como la pesca o la agricultura son perseguidas como ajenas a los objetivos de conservación, el turismo se promueve como una opción sostenible de uso de estos espacios.

De este modo, la conservación contribuye a la restauración y al mantenimiento del poder y el privilegio de clase, un proceso central del proyecto neoliberal (Harvey 2007), al facilitar el acceso y control de áreas valorizadas por su belleza natural por parte de actores poderosos, con el beneplácito del Estado 
(Brokington y Duffy 2010). Al final, en un mundo neoliberal, la conservación se convierte en un lujo, y en un lujo también parecen estar destinados a convertirse los lugares en donde habitan baruleros y providencianos.

En el caso del Estado colombiano en relación con los espacios marítimos, existe un agravante que resulta de la construcción de una nación que, a pesar de tener un área marítima casi tan grande como su porción terrestre, ha defendido históricamente un proyecto político andino. El mar y las costas han desempeñado un papel secundario, que solo ha cobrado fuerza en los últimos años, en la medida en que ganan importancia a través del turismo, el desarrollo de puertos y la explotación de hidrocarburos (CCO 2016). Esta visión ha generado la continua e histórica aplicación de políticas descontextualizadas de las realidades locales y, de manera particular, un desarrollo sin planificación de las regiones costeras, insulares y marinas, que incluye también el abandono creciente de las poblaciones que habitan en estos lugares, junto con el desconocimiento de sus derechos territoriales.

Aunque el panorama presentado puede parecer desolador y sin duda lo es en muchos sentidos, se debe señalar que las comunidades mencionadas no han permanecido pasivas ante lo que ocurre y, por el contrario, han generado diversas resistencias, evidentes y ocultas, frente a procesos que amenazan con arrebatar sus territorios y excluirlos cada vez más. El caso de Providencia, con sus movimientos cívicos y su lucha por mantener el control sobre el territorio, ilustra que es posible utilizar diversas estrategias para la defensa de los espacios de vida, incluso frente a actores poderosos y en el marco de relaciones desiguales. Algo similar puede decirse de Barú donde, en los últimos años, se han adelantado procesos organizativos importantes que buscan defender el territorio que aún queda y oponerse a la exclusión y la desigualdad que avanza ${ }^{27}$.

Para concluir, es necesario llamar la atención sobre la deuda histórica del Estado colombiano con estas regiones y sus pobladores, cada vez más empobrecidos y excluidos. Esto incluye el reconocimiento urgente de la importancia histórica, cultural, social, ambiental, económica, política y simbólica del mar; de la existencia de territorios marítimos y costeros que constituyen un vínculo con el pasado, el presente y el futuro; y de las realidades locales, formas de vida y necesidades socioculturales específicas que se derivan de lo anterior. Implica también el reconocimiento de los derechos territoriales sobre la tierra y el mar

27 Es el caso del fortalecimiento organizativo de los consejos comunitarios de la zona, que han logrado posicionarse y hoy adelantan con fuerza los procesos legales para el reconocimiento de los territorios colectivos, así como la abstención para las elecciones presidenciales del 2014, cuando 2.300 personas se negaron a votar como protesta ante el abandono estatal. 
—y la vida en ellos-, de modo que se privilegien los usos y necesidades locales, así como el control y la autonomía sobre estos.

\section{Referencias}

Agrawal, Arun. 1995. "Dismantling the Divide between Indigenous and Scientific Knowledge”. Development and Change 26: 413-439.

Alcalá, Graciela, ed. 2011. Pescadores en América Latina y el Caribe: espacio, población, producción y política. Ciudad de México: Facultad de Ciencias de la Universidad Nacional Autónoma de México.

Arias Vanegas, Julio y Alhena Caicedo Fernández, eds. 2016. “Antropologías del despojo en Colombia I”. Número especial, Revista Colombiana de Antropología 52 (2).

—. 2017. "Antropologías del despojo en Colombia II". Número especial, Revista Colombiana de Antropología 53 (1).

Barbesgaard, Mads. 2018. “Blue Growth: Savior or Ocean Grabbing?”. The Journal of Peasant Studies 45 (1): 130-149. DOI: 10.1080/03066150.2017.1377186.

Benjaminsen, Tor e Ian Bryceson. 2012. "Conservation, Green/Blue Grabbing and Accumulation by Dispossession in Tanzania”. The Journal of Peasant Studies 39 (2): 335-355. DOI: 10.1080/03066150.2012.667405.

Borras, Saturnino, Ruth Hall, Ian Scoones, Ben White y Wendy Wolford. 2011. "Towards a Better Understanding of Global Land Grabbing: An Editorial Introduction”. The Journal of Peasant Studies 38 (2): 209-216. DOI: 10.1080/03066150.2011.559005.

Brockington, David y Rosalinda Duffy. 2010. "Capitalism and Conservation: The Production and Reproduction of Biodiversity Conservation”. Antipode 42 (3): 469-484. DOI: 10.1111/j.1467-8330.2010.00760.x.

Camus, Pablo, Luis Álvarez, Sebastián Castillo y Rodrigo Hidalgo. 2017. "Bienes comunes, modernización urbano-portuaria y conflicto socio-ambiental. El caso de los pescadores de la caleta Jaime en Valparaíso a principios del siglo XX”. Tiempo Histórico 14: 37-57.

Camus, Pablo y Rodrigo Hidalgo. 2017. “'Y serán desplayados’. Recorrido histórico sobre los bienes comunes, pescadores artesanales y control legal del litoral en Chile”. Historia Crítica 63: 97-116.

Camus, Pablo, Rodrigo Hidalgo y Enrique Muñoz. 2016. "Las disputas por el mar: bienes comunes, pescadores artesanales y pesca industrial. El caso de la caleta Cocholgüe en el litoral centro sur de Chile a mediados del siglo XX”. Población y Sociedad 23 (2): 91-114.

Castree, Noel. 2008. “Neo-Liberalising Nature I: The Logics of de- and Re-regulation”. Environment and Planning $A, 40$ (1): 131-152. 
Chauenpagdee, Ratana y Daniel Pauly. 2004. "Slow Fish: Creating New Metaphors for Sustainability”. En Overcoming Factors of Unsustainability and Overexploitation in Fisheries: Selected Papers on Issues and Approaches, 69-82. Fisheries Report n. ${ }^{\circ} 782$. Camboya: FAO.

Comisión Colombiana del Océano (CCO). 2016. "Política Nacional del Océano y los Espacios Costeros”. Consultado el 14 de diciembre del 2018. http://www.cco.gov.co/pnoec.html.

Consejo Comunitario de Barú. 2017. Barú: los conflictos de la paz. Bogotá: Centro Nacional de Memoria Histórica.

Cordell, John. 1989. “Introduction: Sea Tenure”. En A Sea of Small Boats, editado por John Cordell, 1-31. Cambridge: Cultural Survival.

Corporación Nacional del Turismo (CNT). 1974. "Informe 3: algunas consideraciones relacionadas con el tratamiento espacial de la Isla de Barú. Plan de desarrollo turístico de la costa atlántica. Estudios ecológicos regiones de Santa Marta y Cartagena”. Informe elaborado por Ofisel Ltda.

Crawford, Sharika y Ana Isabel Márquez. 2016. "A Contact Zone: The Turtle Commons of the Western Caribbean”. International Journal of Maritime History 28 (1): 64-80.

Dell’Angelo, Jampi, Maria Cristina Rulli y Paolo D’Odorico. 2018. “The Global Water Grabbing Syndrome”. Ecological Economics 143: 276-285.

Diegues, Antonio Carlos. 1998. Ilhas e mares. Simbolismo e imaginário. São Paulo: NUPAUB; USP.

-. 2001. O mito moderno da natureza intocada. São Paulo: NUPAUB/USP; Editora Hucitec.

Durán, Carlos. 2007. ¿Es nuestra isla para dos? Conflicto por el desarrollo y la conservación en islas del Rosario, Cartagena. Bogotá: Ediciones Uniandes.

Fairhead, James, Melissa Leach e Ian Scoones. 2012. "Green Grabbing: A New Appropriation of Nature?”. Journal of Peasant Studies 39 (2): 237-261. DOI:10.1080/03066150.2012.67 1770 .

García-Quijano, Carlos G., John J. Poggie y Miguel H. del Pozo. 2015. "En el monte también se pesca: 'pesca de monte', ambiente, subsistencia y comunidad en los bosques costeros del sureste de Puerto Rico”. Caribbean Studies 43 (2): 115-144.

Grajales, Jacobo. 2011. "The Rifle and the Title: Paramilitary Violence, Land Grab and Land Control in Colombia”. The Journal of Peasant Studies 38 (4): 771-792. DOI: 10.1080/03066 150.2011.607701.

Heckadon, Stanley. 1970. "El Islote. Estudio socioeconómico sobre una comunidad de pescadores, islas de San Bernardo”. Tesis de pregrado en Antropología, Universidad de los Andes, Bogotá.

Harvey, David. 2007. Breve historia del neoliberalismo. Madrid: Akal.

Heynen, Nik y Paul Robbins. 2005. "The Neoliberalization of Nature: Governance, Privatization, Enclosure and Valuation”. Capitalism Nature Socialism 16 (1): 5-8. DOI: $10.1080 / 1045575052000335339$.

Mansfield, Becky. 2004. "Neoliberalism in the Oceans: 'Rationalization', Property Rights and the Commons Question”. Geoforum 35: 313-326. DOI: 10.1016/j.geoforum.2003.05.002. 
Márquez, Ana Isabel. 2005. "Los pescadores artesanales de Old Providence Island: una aproximación al estudio de las relaciones seres humanos-medio ambiente”. Monografía de grado en Antropología, Universidad Nacional de Colombia.

-. 2012. "Catboats, Lanchs and Canoes: la construcción y el uso de embarcaciones de madera en las islas de Old Providence y Santa Catalina, un patrimonio cultural en peligro”. Informe final presentado ante Colciencias. Inédito.

-. 2013. Fi Wi Sea/Nuestro mar/Our Sea. Historias y memorias del mar isleño raizal. Bogotá: Instituto Colombiano de Antropología e Historia (ICANH).

-. 2014. "Povos dos recifes: reconfigurações na apropriação social de ecossistemas marinhos e litorâneos em duas comunidades do Caribe”. Tesis doctoral en Antropología, Universidade Federal Rural de Rio de Janeiro, Río de Janeiro.

-. 2017. "Memorias del mar: la conformación del territorio marítimo raizal de los Cayos del Norte del archipiélago de San Andrés, Providencia y Santa Catalina, por medio de la memoria y la historia oral”. En Memoria y territorio, coordinado por Beatriz Nates, 261-280. Bogotá: Instituto Colombiano de Antropología e Historia.

Martínez, Claudia y Gonzalo Uribe. 1975. "Barú: un pueblo en la costa norte de Colombia, sus problemas y sus enseñanzas”. Trabajo de grado en Antropología, Universidad de los Andes, Bogotá.

McCarthy, James y Scott Prudham. 2004. "Neoliberal Nature and the Nature of Neoliberalism”. Geoforum 35: 275-283. DOI: 10.1016/j.geoforum.2003.07.003.

McCay, Bonnie y James Acheson. 1987. "Introduction: A Human Ecology of the Commons". En The Question of the Commons. The Culture and Ecology of Communal Resources, editado por Bonnie J. McCay y James M. Acheson, 1-36. Tucson: University of Arizona Press.

Medrano, Enrique, José Bolaño Medrano, Wilner Gómez Rodríguez, Nicolás Valencia Gómez, Miguel Ángel Geles Villamil, Rocío del Pilar Moreno-Sánchez, Sandra Lucía Mendoza Mojica y Jorge Higinio Maldonado. 2015. El pescador de Barú: una aproximación a la recuperación del conocimiento local asociado a la pesca. Bogotá: Ediciones Uniandes.

Mehta, Lyla, Jan Veldwisch Gert y Jennifer Franco. 2012. "Introduction to the Special Issue: Water Grabbing? Focus on the (Re)appropriation of Finite Water Resources”. Water Alternatives 5 (2): 193-207.

Mosquera, Claudia, Luiz Barcelos y Andrés Arévalo. 2007. “Contribuciones a los debates sobre las memorias de la esclavitud y las afro-reparaciones en Colombia desde el campo de los estudios afrocolombianos, afrolatinoamericanos, afrobrasileros, afroestadounidenses y afrocaribeños”. En Afro-reparaciones: memorias de la esclavitud y justicia reparativa para negros, afrocolombianos y raizales, editado por Claudia Mosquera y Luiz Barcelos, 11-70. Bogotá: Universidad Nacional de Colombia.

Nietschmann, Bernard. 1989. "Traditional Sea Territories, Resources and Rights in Torres Strait”. En A Sea of Small Boats, editado por John Cordell, 60-93. Cambridge: Cultural Survival.

OCDE. 2016. "Pesca y acuicultura en Colombia. Informe de Antecedentes”. Consultado el 5 de octubre del 2018. https://www.oecd.org/agriculture/fisheries/Fisheries_Colombia_SPA_ rev.pdf. 
Ojeda, Diana. 2012. "Green Pretexts: Ecotourism, Neoliberal Conservation and Land Grabbing in Tayrona National Natural Park, Colombia”. The Journal of Peasant Studies 39 (2): 357-375. DOI: 10.1080/03066150.2012.658777.

Organización de la Comunidad Raizal con Residencia fuera del Archipiélago de San Andrés, Providencia y Santa Catalina (ORFA). 2016. "Plan Especial de Salvaguardia (PES) para saberes, conocimientos ancestrales y prácticas culturales raizales en su convivencia con el mar”. Inédito.

Orlove, Ben y Mattias Rasmunssen, eds. 2015. "Anthropologists Exploring Water in Social and Cultural Life: Introduction”. American Anthropologist. https://anthrosource.onlinelibrary.wiley.com/hub/journal/15481433/exploring-water.

Parsons, James. (1956) 1985. San Andrés y Providencia, una geografía histórica de las islas colombianas del mar Caribe. Bogotá: Banco de la República.

Pauly, Daniel. 2006. "Major Trends in Small Scales Marine Fisheries, with Emphasis on Development Countries, and Some Implications for the Social Sciences”. MAST 4 (2): 7-22.

Pedraza, Zandra. 1984. “We was one family’: recopilación etnográfica para una antropología de Providencia”. Trabajo de grado en Antropología, Universidad de los Andes, Bogotá.

Peron, Françoise y Jean Riecau. 1996. Introducción a La maritimité aujourd'hui, organizado por Françoise Peron y Jean Riecau, 13-54. Collection Geographies et Cultures. París: Editions L'Harmattan.

Ploeg, Jan van der. 2008. Camponeses e impérios alimentares. Lutas por autonomia e sustentabilidade na era da globalização. Porto Alegre: UFRGS.

Rivera, María Camila. 2012. "Tan solo deja la huella de tu piel sobre la arena. Providencia: más allá de la etnicidad y la biodiversidad, una insularidad por asumir”. Tesis de Maestría en Estudios Culturales, Pontificia Universidad Javeriana, Bogotá.

Shiva, Vandana. 2003. Monoculturas da mente. Perspectivas da biodiversidad e da biotecnología. São Paulo: Editora Gaia.

Toledo, Víctor y Narciso Barrera-Bassols. 2008. La memoria biocultural. La importancia ecológica de las sabidurías tradicionales. Madrid: Icaria.

Unidad Administrativa Especial de Parques Nacionales Naturales (UAESPNN). 2006. Plan de Manejo del Parque Nacional Natural Corales del Rosario y San Bernardo. Cartagena: Territorial Caribe.

Vélez-Torres, Irene. 2012. "Water Grabbing in the Cauca Basin: The Capitalist Exploitation of Water and Dispossession of Afro-Descendant Communities". Water Alternatives 5 (2): 431-449.

Wachtel, Nathan. 1999. "Memoria e historia”. Revista Colombiana de Antropología 35: 70-90.

Wilson, Peter. 1973. Crab Antics. A Caribbean Study of the Conflict between Reputation and Respectability. Illinois: Waveland Press.

World Forum of Fisher Peoples (WFFP). 2014. "El acaparamiento mundial de los océanos. Guía básica”. Consultado el 12 de diciembre del 2017. https://www.tni.org/files/download/ the_global_ocean_grab-es.pdf. 